\title{
DE LOS CANTAUTORES AL ROCK RADICAL. UNA APROXIMACIÓN A LA MÚSICA POPULAR Y JUVENTUD EN LA VIDA POLÍTICA DEL PAÍS VASCO (1960-1990)
}

\author{
FROM SINGER-SONGWRITERS TO RADICAL ROCK. \\ AN APPROACH TO POPULAR MUSIC AND YOUTH \\ IN THE POLITICAL LIFE OF THE BASQUE COUNTRY
}

(1960-1990)

Ander Delgado

$\mathrm{UPV} / \mathrm{EHU}$

ORCID: https://orcid.org/0000-0003-2264-7182

Ekaitz Etxezarreta

UPV/EHU

ORCID: https://orcid.org/0000-0002-3589-2649

Recibido el 19-10-2017 y aceptado el 20-2-2018

Resumen: El objetivo de este artículo es analizar la relación existente entre varios estilos musicales y la vida política de los jóvenes en el País Vasco entre las décadas de los sesenta y ochenta del siglo XX. En este texto se propone un desarrollo de esta relación, de sus características básicas y de las razones que explican algunos de los procesos observados durante estos años. Partiendo de la importancia que juega la música popular entre los jóvenes, a través de este estudio también se busca realizar una primera aproximación al estudio de sus formas de acción política cotidianas. El estudio se centra en el Euskal Kantagintza Berria de los años sesenta y setenta y el Rock Radical Vasco de los ochenta.

Palabras clave: País Vasco, música popular, política, nacionalismo, cantautores, punk. 


\begin{abstract}
The aim of this article is to analyse the relationship between different musical styles and the Basque youth political life from sixties to eighties of $\mathrm{xx}^{\text {th }}$ Century. This text presents a development of this relationship, its main characteristics and explanations about some processes happened during these years. Taking into account the important role of the music among young, this research also wants to make a first approach to their everyday life forms of political action. The research deals with the Basque New Music movement of the sixties and seventies and Basque Radical Rock of the eighties.
\end{abstract}

Keywords: Basque Country, popular music, politics, nationalism, singersongwriter, punk. 
Cuando se utilizan los términos música popular y juventud en una misma frase las ideas que pueden venir a la cabeza de muchos/as lectores/as pueden ser, por ejemplo, diversión, evasión, hedonismo o desinhibición. Sin embargo, en este artículo también se toma en consideración un tercer elemento a los conceptos inicialmente mencionados: la política en su sentido más amplio. Sin negar la importancia de la diversión al hablar de la música popular, diferentes estilos musicales, desde el blues al rap, pasando por la canción protesta o el punk, han tenido una fuerte carga política a lo largo de la historia contemporánea. Bien como forma de expresión de ideales o proyectos políticos, de denuncia de situaciones sociales injustas o, en otras ocasiones, de difusión de valores e identidades nacionales determinadas ${ }^{1}$.

Partiendo de esta idea, en este artículo se analizan algunos de los movimientos musicales que se desarrollaron en el País Vasco entre los años sesenta y los ochenta del siglo pasado y la forma en la que se interrelacionaron con la vida política juvenil de aquellos años. Dentro de este contexto temporal intenso y convulso, en este artículo se presta atención a los movimientos musicales del Euskal Kantagintza Berria [Nueva Canción Vasca] de los años sesenta y setenta y del movimiento punk, el Rock Radical Vasco (RRV) y la música Oi! de la siguiente década; estilos que se pueden considerar como los más socialmente influyentes de aquellos años. El objetivo de este artículo es realizar una aproximación a la relación existente, en ambas direcciones, entre estos movimientos musicales y la política vasca, especialmente con el nacionalismo vasco, de finales del régimen franquista, la Transición y consolidación del régimen democrático actual. De hecho, su finalidad es presentar una propuesta de evolución de esta relación durante un periodo de intensa vida política como fueron estos años que pueda servir de hipótesis de trabajo para futuras investigaciones.

Esta investigación sigue un acercamiento que se podría denominar como «historia sociopolítica de la música popular». Este enfoque se acerca al estudio de estos movimientos musicales como forma de enriquecer el conocimiento sobre la vida política de esta época. Se parte de la idea de que la música, así como los conciertos, estaban integrados en la vida diaria de muchas personas, especialmente jóvenes, de aquellos años.

${ }^{1}$ Un acercamiento a las formas de relación entre la cultura popular, en cuyo seno la música juega un papel fundamental, y la política se pueden observar en Street (2000 y 2012) o Rowe (1995: cap. 3). 
Los conciertos, además, eran actos colectivos donde se reunía un importante número de gente y que servía de momento de sociabilidad, diversión y, no menos importante, de expresión de malestar, ideas políticas e identidad. Por ello, el estudio de la música popular puede servirnos para adentrarnos en las características de esta vida política prestando atención a algunos aspectos no tan estudiados. Si bien hay muchos estudios sobre la política de los años del final del Franquismo y la consolidación de la democracia, es menos la información que se tiene sobre las prácticas políticas y sociales cotidianas alejadas de los canales de participación políticos más «organizados» como las manifestaciones, huelgas, elecciones o, si se quiere, del propio uso de la violencia. De ese modo se puede ampliar el enfoque de análisis desde los colectivos más movilizados y activos a un entorno social más amplio que podía estar alejado del activismo y militancia directa, pero no por ello ajenos al contexto sociopolítico en el que vivían y dispuestos a expresar su malestar y opiniones cuando ello era posible. Este acercamiento puede ayudarnos a conocer mejor la extensión de la movilización política en estos años, las formas de acción política cotidianas y el impacto de los diferentes debates ideológicos en sectores sociales más amplios.

Si la historiografía sobre la política vasca del periodo elegido es amplia, los estudios sobre los estilos musicales mencionados no lo son menos. En los últimos años ha aumentado significativamente su número, tanto referidos al Euskal Kantagintza Berria como al RRV y su contexto. En estos estudios, algunos de los cuales se citan a lo largo de este texto ${ }^{2}$, ha sido más habitual, y lógico por otra parte, un acercamiento centrado en la historia y desarrollo de los grupos musicales, sus integrantes y sus canciones y letras. Estas obras aportan una información relevante y fundamental para seguir el camino propuesto aquí. Para ello se utilizan las menciones y datos que aparecen citados de forma dispersa en muchos de estos trabajos pero que ahora, junto con otras fuentes de información, se quieren analizar en su conjunto y proponer un esquema de desarrollo de este ámbito.

Dentro de esta investigación resulta interesante prestar atención a lo que se podría denominar como la «experiencia social de la música» como

2 Dada la amplitud de este corpus de publicaciones sobre música vasca y las limitaciones de espacio en un artículo como éste, sólo se mencionan las obras utilizadas o consideradas más relevantes para esta investigación. Sin que eso prejuzgue la calidad ni interés de las no citadas. 
forma de expresión política y experiencia identitaria. Es decir, cómo (no sólo) la gente joven utilizaba la música y, sobre todo, los conciertos como forma de protesta y de expresión de sus ideales, así como para construir su propia identidad. Autores como John Street, Simon Frith o Peter J. Mar$\operatorname{tin}^{3}$ han señalado la importancia que juega la música popular en la construcción de la identidad personal, el surgimiento de una solidaridad grupal y la diferenciación del «nosotros» respecto de los «otros». Estos autores han señalado la importancia de la experiencia personal en la participación en actividades organizadas en torno a la música y el «consumo» de ésta en la configuración de la identidad personal. Consideran que la música no debe considerarse como mera representación o reflejo de una serie de valores de una sociedad, sino como elemento clave en la experiencia personal que ayuda a la construcción del «yo» y el «nosotros» por permitir una percepción de lo subjetivo y lo colectivo en un contexto determinado. «La música construye nuestro sentido de la identidad mediante las experiencias directas que ofrece del cuerpo, el tiempo y la sociabilidad, experiencias que nos permiten situarnos en relatos culturales imaginativos ${ }^{4}$. El movimiento de cantautores de los sesenta y setenta conocido como Euskal Kantagintza Berria es un buen ejemplo de ello. Este movimiento musical fue una forma de expresar opiniones políticas y el malestar social de la juventud en el contexto represivo, tanto político como cultural, del Franquismo. Uno de los más destacados cantantes y poetas de este grupo, Xabier Lete, reflejaba bien esta circunstancia en el título de un artículo suyo sobre este movimiento musical publicado en $1977^{5}$. Lo titulaba «Kanta Berria, erresistentzi kanta» [Nueva canción, canción de resistencia] y conecta con esa idea de la música como forma cotidiana de acción política y expresión de disenso en el Franquismo. Lo mismo cabe decir cuando durante los años ochenta en muchos conciertos el público (o parte de él) podía corear eslóganes a favor de $\mathrm{ETA}^{6}$ o realizar otros actos de propaganda política de la Izquierda Abertzale.

El investigador estadounidense Jonathan Pieslak realiza una serie de comentarios interesantes sobre el papel que podían jugar los conciertos en la identificación ideológica del público asistente con algunos movimientos radicales y violentos. Sin negar la importancia del mensaje radical de

\footnotetext{
3 Street, 2000, pp. 24-25; Frith, 2003 y Martin, 2006.

4 Frith, 2003, p. 212.

5 Lete, 1977.

6 Sánchez Ekiza, 2013, p. 48.
} 
las canciones que estudia, este autor destaca que el ritual del concierto y el sonido pueden ser, en un inicio, elementos fundamentales para conectar al oyente con esos movimientos. De hecho, comenta, en algunas canciones resulta difícil entender las letras por la propia forma de ser cantada, el ritmo, el idioma, etc., a pesar de lo cual consigue atraer a posibles seguidores de dichos movimientos. Otros autores también han señalado que incluso las letras de las canciones pueden tener impacto político sin necesidad de tener referencias explícitamente políticas. Éstas pueden ser entendidas dentro de un contexto político o de lucha determinado en el que pueden adquirir sentido para el oyente sin necesidad de ser explícitas e, incluso, con el tiempo puede cambiar la atribución que se le da a la canción ${ }^{7}$. Por eso Pieslak considera que la atracción del sonido y el ritmo y el contexto en el que se consume la música puede preceder a la propia identificación con las letras o los postulados que defiende el estilo musical. La música puede catalizar una adhesión emocional previa al compromiso ideológico ${ }^{8}$. En ese sentido, el estudio de los conciertos en el País Vasco, donde en muchas ocasiones lo político tenía un papel relevante, pueden adquirir relevancia en un análisis como el propuesto en este artículo. Si bien en el caso que se analiza, la consecuencia de consumir esa música en los conciertos no lleva implícito necesariamente la adhesión a ninguna organización política determinada, sí habla de la importancia que pudo jugar en este periodo la participación en acontecimientos colectivos como los conciertos para muchos jóvenes. Y esa vivencia de la música puede conectar con la idea de que la música, además de transmitir una memoria o un mensaje, proporciona una experiencia colectiva que refuerza el sentimiento de pertenencia a algo más grande que lo propiamente individual del oyente ${ }^{9}$.

\section{Los años sesenta y setenta: Euskal Kantagintza Berria ${ }^{10}$}

Desde inicios de los años sesenta la historia de la música vasca entró en una nueva fase. Se puede considerar que se produjo una suerte de boom

7 Ballinger, 1999, p. 61.

${ }^{8}$ Pieslak, 2015, pp. 196-197. Aquí se destaca la idea de la vinculación entre los conciertos y la movilización política que realiza este autor, más allá del estudio de los movimientos radicales que el autor realiza.

9 Eyerman, 2002, p. 452.

10 Un análisis más amplio de este apartado se puede localizar en Delgado, 2016. 
musical en el que fueron apareciendo, especialmente desde finales de esa década, un importante número de solistas o grupos repartidos por todo el País Vasco, a los dos lados de la frontera. La publicación de dos discos, entre los años 1961 y 1963, por el médico vascofrancés Michel Labeguerie se ha considerado el inicio de todo este movimiento. Su difusión a este lado de la frontera causó un gran impacto entre muchos jóvenes que constataron que se podía cantar en euskera en otros estilos musicales diferentes, y más actuales, de los considerados tradicionalmente unidos a los vascos. Además de ser una buena forma para expresar sus vivencias y, sobre todo, su malestar por la situación que les tocaba vivir. Estos cantantes, mayormente, recurrieron al cancionero popular, a los bertsos o a nuevos poemas publicados aquellos años y componían sus canciones haciéndose eco de estilos como la canción folk estadounidense, la música francesa, la canción protesta latinoamericana, la nova canço... y otros estilos musicales del momento ${ }^{11}$.

El camino abierto por Labeguerie fue seguido, en esa primera mitad de los años sesenta, por muchos jóvenes que deseaban expresar sus inquietudes musicales. Inquietudes que conectaron con las de la juventud de la época, dado que estos cantantes adquirieron una popularidad destacable. Figuras tan conocidas, entre otras muchas, como Lurdes Iriondo, Mikel Laboa, Benito Lertxundi o Xabier Lete comenzaron su andadura musical en estos años. El proceso de aparición de cantantes y de creación de bandas se intensificó desde mediados de los años sesenta, pero, fundamentalmente, en la siguiente década. En estos años aparecieron cantantes como Imanol, Urko, Maite Idirin, Txomin Artola, Estitxu, Gontzal Mendibil, Gorka Knorr, Pantxoa eta Peio..., grupos Folk como Lantzale, Oskorri, Izukaitz o Haizea o más cercanos al Rock como Errobi o Itoiz. Cantantes y grupos que junto con los de la década anterior, que seguían actuando, crearon una extensa escena musical en el País Vasco, que iba también más allá de los artistas aquí estudiados ${ }^{12}$.

$\mathrm{Al}$ margen de otras finalidades de carácter artístico de este movimiento musical (p.ej., modernizar la música vasca), uno de sus objetivos era extender el uso del euskera en la sociedad vasca como medio de reforzar la len-

11 Aristi, 1985, pp. 18-24. Así lo menciona, por ejemplo, Xabier Lete, 2011, pp. 37-38. O Maite Idirin, quien mencionaba que al escuchar estos dos discos se puso a llorar y fue ése el momento en el que decidió que ella también iba a cantar. Velez de Mendizabal, 2011.

12 Aristi, 1985; Oronoz, 2000; Iriondo, 2001; López Aguirre, 2011 o Larrinaga, 2016. 
gua, la cultura y la identidad vasca, que se consideraban estaban en peligro por los cambios sociales de aquellos años, en especial la fuerte inmigración, y las políticas culturales del régimen franquista. El hecho de cantar en euskera era una forma de defender la lengua y la cultura vasca consideradas en peligro. La defensa de la lengua aparecía unido también a la defensa de la identidad nacional vasca o, cuando menos, una visión básica de la patria vasca, en claro peligro, según muchos ${ }^{13}$. Haciendo esto, a la vez, se hacía antifranquismo dado que la defensa de la cultura vasca era una forma de hacer frente a las políticas del régimen que se consideraban la atacaban y pretendían imponer la cultura «española» uniformizadora. La canción se convirtió, en consecuencia, en el vehículo más adecuado para exponer inquietudes sociales, culturales y políticas ${ }^{14}$. Las características que se acaban de mencionar conferían a estas canciones un contenido político relevante en el contexto del Franquismo. El público asistente a los conciertos lo hacía, entre otras cosas, para escuchar un mensaje político genérico que no se podía escuchar en otro lugar durante el Franquismo ${ }^{15}$ o, quizás, solo participar de una actitud personal de los/as cantantes que con el hecho de subir al escenario dejaban patente el eje básico de la lucha con la que se sentían concernidos ${ }^{16}$. Es fácil de entender, en definitiva, el impacto político y emocional de estas canciones y los conciertos entre la parte de la sociedad vasca que estaba de acuerdo en lo básico con esa lucha ${ }^{17}$.

Las fuerzas policiales del régimen franquista eran conscientes de esta realidad. En varios informes policiales se mencionaba que se aprovechaban las fiestas patronales, entre cuyos actos más destacados estaban las verbenas y los conciertos, para hacer actos de propaganda. Ya en 1966, en un informe del Gobierno Civil de Bizkaia se señalaba que «Los separatistas vascos, alentados principalmente por los sacerdotes de esta ideología, han continuado con sus actividades propagandísticas, aprovechando especialmente los festejos que en la época estival se celebran en la mayoría de los pueblos, repartiendo alguna propaganda y pintando letreros» ${ }^{18}$. En

${ }^{13}$ Estornés, 2010b.

14 Garaia, n. ${ }^{\circ} 25,17-24.02 .1977$, p. 37.

15 Temas como la libertad, la protesta, la esperanza, la injusticia, Martin Luther King, Vietnam... Aristi, 1985, p. 36.

16 Lete, 1977, pp. 17-18.

17 Lete, 1977, p. 19, y Elorza, 2010, pp. 57-58.

18 Servicio de Microfilmación del Departamento de Historia Contemporánea (UPV/ EHU), Fondo Gobierno Civil de Bizkaia (en adelante, SMDHC-FGC), rollo 1. Gobierno Civil de Bizkaia, Parte de Información Trimestral, 3. . Trimestre 1966. 
otro de la Jefatura Superior de Policía de Bilbao de septiembre de 1970 también se volvía a señalar que "Los elementos SEPARATISTAS, al no poder hacer otra cosa, encuentran su válvula de escape organizando actos vasquistas, representaciones teatrales, folklóricas, canciones, etc. aprovechando las fiestas Patronales de sus respectivas zonas» ${ }^{19}$. Situación que se volvía a repetir en otro informe de 1973 cuando se señalaba que durante el verano las organizaciones nacionalistas volvían a utilizar las fiestas patronales «en las que abundan romerías y festejos de carácter típico (canciones vascas etc.), que se prestan a la realización de actos de agitación, como de hecho ha sucedido en algunas poblaciones» ${ }^{20}$.

A pesar de que las autoridades conocían esta situación, éste era un tema difícil de gestionar. En un principio, no se prestó especial atención a esta actividad de carácter musical, al haber otros temas de mayor importancia para las fuerzas de orden público (los comunistas, ETA...). Se puede decir que hubo una suerte de «tolerancia» ante estas actividades $^{21}$. Pero cuando su importancia política se fue haciendo cada vez más evidente, se comenzó a controlarla más. Sin embargo, y aunque el Gobernador Civil de Gipuzkoa lo intentó en 1969 con el colectivo Ez dok amairu prohibiendo a sus miembros actuar durante dos años ${ }^{22}$, se impusieran multas a cantantes, existiera un rígido procedimiento de censura previo a la autorización y celebración de los conciertos o se suspendiera algún concierto $^{23}$, resultaba difícil prohibir todos o muchos de los conciertos a celebrar en el País Vasco de todo el amplio colectivo de cantantes mencionado, sin que el régimen quedara retratado como duramente represivo. Muchos de ellos, además, estaban organizados dentro de

19 SMDHC-FGC, rollo 1. Jefatura Superior de Policía de Bilbao, Boletín Informativo Semanal $1^{\text {a }}$ semana de septiembre de 1970.

20 SMDHC-FGC, rollo 2. Boletín Informativo Regional, 28 julio al 4 agosto de 1973.

${ }^{21}$ Lete, 1977, p. 20 y Aristi, 1985, pp. 50-52. «Tolerancia», es necesario señalar, para todos aquellos cantantes y organizadores de conciertos que conseguían superar todas las trabas establecidas por el sistema de censura de la época.

22 Knörr, 1977, p. 12, y Oronoz, 2000, p. 62. Gorka Knörr también vivió esta situación: se le prohibió tocar en Bizkaia durante tres años, en Gipuzkoa se le denegaban los permisos para cantar por meses, se le quitó el pasaporte entre 1974 y 1976 e incluso el permiso de conducir durante esos años. Punto y Hora de Euskal Herria, 7-13.04.1977, p. 35.

23 Así se hizo, por ejemplo, con el ««Festival de la Canción Vasca de Salvatierra» [...] previendo fuera una manifestación de separatismo». SMDHC-FGC, rollo 1. Boletín Informativo Regional, 2 al 8 diciembre de 1972. 
las fiestas patronales locales y contaban con el apoyo expreso de las autoridades municipales afines del régimen ${ }^{24}$. En otras ocasiones, tenían una finalidad solidaria para recaudar fondos, por ejemplo, para las ikastolas. Por ello era complejo establecer una prohibición de carácter general a estos conciertos a pesar de que las autoridades considerasen que cumplían una finalidad política contraria al régimen franquista. Pero incluso cuando los conciertos se estaban desarrollando y el público asistente comenzaba a gritar eslóganes, se izaba alguna ikurriña o realizaban otros actos políticos, resultaba complicado para las fuerzas policiales disolver a todo el público asistente, por lo menos, sin provocar problemas de orden público. Por todo ello, el control del régimen sobre este movimiento se realizó sobre todo a través de la censura de las letras.

En el desarrollo del Euskal Kantaginza Berria se observa la existencia de una serie de transformaciones con el cambio de década. Si bien las características mencionadas se pueden aplicar de forma general a las dos décadas analizadas en este apartado, se puede observar una diferencia notable entre los años sesenta respecto de la siguiente década en lo que respecta a las letras y a las relaciones de diferentes organizaciones políticas de la época con este movimiento musical. Se puede considerar que se sumaron a unos mensajes genéricos de defensa de la cultura y de las inquietudes de la juventud otros discursos más conectados con acercamientos ideológicos sobre la problemática nacional y obrera vasca. Además, era fácil observar una mayor división partidista entre el público y los cantantes. Hay autores que señalan que desde 1973, aunque más claramente desde 1976, se constata el inicio de los conciertos políticos en el País Vasco y la aparición de unas letras más explícitas ${ }^{25}$.

El contexto de los últimos años del Franquismo y el inicio de la Transición trajo consigo una serie de cambios tan destacados que este movimiento musical no se pudo quedar al margen de ellos. Si la música vasca era tan importante en la política de la época, los cambios ocurridos en el ámbito político terminaron por afectar también a la música. Podrían ser múltiples los elementos de este periodo que cabrían mencionarse, aunque para los objetivos de este artículo se destaca la ruptura de la unidad en el nacionalismo vasco de izquierdas, por explicarlo de una forma muy sintética, entre una corriente que enfatizaba el aspecto nacio-

${ }^{24}$ Lete, 2011, p. 44.

25 Aristi, 1985, pp. 120-121. 
nalista vasco frente a otro colectivo que evolucionó hacia un obrerismo internacionalista de corte marxista donde el elemento «nacional» no jugaba ese papel tan destacado ${ }^{26}$. División y lucha partidista que se hizo más evidente al inicio de la Transición cuando se fueron creando diversas organizaciones políticas para desarrollar su actividad en el nuevo régimen democrático que daba sus primeros pasos. Esta circunstancia se dejó notar en que la mayoría de las organizaciones políticas del entorno del nacionalismo vasco de izquierdas intentaron controlar o, cuando menos, influir en la dirección de este movimiento musical sabedores de su importante papel de propaganda y socialización política. La cultura en sentido amplio, también la música, tenía un papel que jugar en el proceso de liberación nacional o de revolución social al ser considerada una forma más de acción política y, por ello, tenía que estar al servicio de los objetivos impulsados o dentro de las coordenadas defendidas por las organizaciones políticas ${ }^{27}$. Característica que no todos los cantantes aceptaron de buen grado por la limitación a su creatividad artística que esto suponía.

Mientras algunos cantantes parecían querer mantener su creatividad artística al margen de la excesiva injerencia de las organizaciones políticas, otros muchos se caracterizaron por lo contrario: desarrollar una carrera en la que la consecución de unos objetivos políticos determinados era primordial y donde su implicación en la política partidista y militante era evidente. Son varios los ejemplos que se pueden encontrar de esta evolución. El conocido grupo folk Oskorri, que inició su larga andadura en 1971, manifestaba claramente el objetivo político de su actividad artística en una entrevista realizada al año siguiente. Sin restar importancia a los aspectos musicales y estéticos de su labor, sus integrantes destacaban que su objetivo fundamental era sacar a relucir las necesidades políticas del Pueblo Vasco e intentar darles una solución. Añadiendo, dentro de los debates en el seno del nacionalismo de izquierdas, que había diferentes formas de ser abertzale en aquellos momentos, a lo que un articulista anónimo añadía que su objetivo estaba

${ }^{26}$ El ejemplo más conocido de este proceso fue la división de ETA, desde su VI Asamblea de 1970 en adelante, en diferentes organizaciones siguiendo el eje mencionado. También fue influyente, pero menos conocida, la división del sindicato nacionalista ELA-STV y el surgimiento de ELA-Berri, organización que intentó fusionar el socialismo con el nacionalismo vasco (Estornés, 2010a).

27 Lete, 1977, p. 17, y Iztueta, 1985, p. 399. 
claro: preocuparse por la clase trabajadora ${ }^{28}$. Circunstancia que situaba al grupo en la línea obrerista internacionalista dentro del debate mencionado más arriba. El cantante Imanol Larzabal también partía de un claro posicionamiento político, que se intensificó notablemente durante su exilio francés. De hecho, este cantautor señalaba que comenzó a cantar en 1969 con la finalidad de crear una conciencia política en el País Vasco que él consideraba no estaba suficientemente desarrollada. Entre 1969 y 1971 , el periodo que va desde su estancia en la cárcel y su huida al exilio por su militancia en ETA, consideraba que su labor como cantante debía estar unida a la consecución de los objetivos políticos que defendía, para lo cual cualquier labor de propaganda o agitación era positiva $^{29}$. Otro ejemplo de lo mencionado puede ser también el caso de Jose Antonio Larrañaga, Urko, quien comenzó a publicar sus discos en 1976, quien señalaba que su objetivo era cantar canciones políticas. Consideraba que ante el problema nacional había que ser radical y, por tanto, sus canciones también vivieron un proceso de radicalización. «Pienso una cosa, como pueblo estamos en lucha y había que politizar la canción a la fuerza. Había que decir una serie de cosas y hubiera sido engañar al pueblo no decirlas. Estas cosas eran evidentemente políticas». Por todo ello, en esa misma entrevista realizada en 1977, no ocultaba su identificación con ETA (político militar) y su recién creado partido político EIA [Euskal Iraultzarako Alderdia o Partido para la Revolución Vasca], antecedente de Euskadiko Ezkerra ${ }^{30}$.

La intensificación de la movilización política en los años setenta unido a la división organizativa del nacionalismo de izquierdas creó un contexto de politización y radicalización notable en la sociedad vasca. Los efectos de esta situación también se dejaron notar en los conciertos de la época. Tanto el público como algunos organizadores de conciertos buscaban una mayor implicación política de los cantantes y que su trabajo y actuaciones se hicieran eco de la radicalización de la sociedad. Y esta situación tuvo una incidencia directa en muchos conciertos. El cantante Antton Valverde expresaba claramente esta situación:

${ }^{28}$ Anaitasuna, n. ${ }^{\circ} 239,15.08 .1972$, y n $^{\circ}{ }^{\circ} 240,15.09 .1972$.

${ }^{29}$ El propio cantante reconocía, más adelante, que durante estos años su postura política fue muy radical al supeditar su actividad artística a la política, hecho que a posteriori consideraba había sido una postura inadecuada y que los que optaron por la línea contraria acertaron (Aristi, 1985, pp. 95-97 y 104-106, y López Aguirre, 2011, pp. 102-103).

${ }^{30}$ Punto y Hora de Euskal Herria, 14-20.04.1977, p. 35. 
Cuando poco a poco fue abriéndose el puño y se podía empezar a cantar con más tranquilidad, se utilizó el movimiento de la canción vasca con fines totalmente ajenos a lo que puede ser la canción en sí, de mutuo acuerdo implícito entre cantantes y público, la gente iba a los festivales a ver una ikurriña ondeando allí, a gritar Gora Euskadi Askatuta y cosas de esas. ${ }^{31}$

Este proceso, sin embargo, comenzó, por lo menos, desde inicios de los años setenta. Así lo indican las palabras del miembro de $E z$ dok amairu Joxan Artze al señalar que «orduan jendea biltzeko ia-ia beste aukerarik, beste gunerik ez zegoenez, mitin politikoak egiteko baliatu zituzten batzuek gure emanaldiak [...]. Emanaldiak eteten zuten aldarriak egiteko, eta sekulako iskanbilak sortzen zituzten» ${ }^{32}$. Circunstancia, que como se ha comentado, no fue del agrado de varios de los integrantes de este colectivo. Aunque esta situación se hizo más evidente en la medida que transcurrían los años, cuando el impacto de la vida política, cada vez más intensa y radical, tuvo una incidencia cada vez mayor en el desarrollo de muchos conciertos. Éstos se convirtieron casi más en un momento de propaganda que de disfrute artístico, atendiendo a las interrupciones en los conciertos por los eslóganes y gritos del público dejando patente su posicionamiento político. Y muchas veces los cantantes debían interrumpir sus actuaciones hasta que el público decidiera parar. Así le ocurrió a Urko cuando presentaba su disco Hemen Gaude de 1977 en un concierto: a mitad de la primera canción dos encapuchados subieron al escenario, interrumpieron la canción y colocaron una ikurriña ${ }^{33}$. En otras ocasiones, cuando entre el público había gente de diferentes sensibilidades políticas podían darse situaciones de tensión. Consignas como «Gora Euskadi askatuta!» o «Gora Euskadi gorria!» [¡Viva Euskadi libre! o ¡Viva Euskadi roja!] eran habituales entre el público. Estas consignas reflejaban la división que se ha mencionado dado que la primera hacía referencia a una militancia más marcadamente nacionalista vasca mientras la segunda conectaba con aquellos que siguieron la línea del frente obrero marxista. Una situación de este tipo se dio, por ejemplo, en un

31 Citado en Aristi, 1985, p. 124.

32 Entonces como la gente casi no tenía oportunidad, ni había lugares para reunirse, algunos aprovechaban nuestros conciertos para hacer mítines políticos [...]. Solían detener los conciertos para gritar consignas, y creaban enormes escándalos. [Traducción del autor]. Zabala, 2003, p. 37.

33 Aristi, 1985, p. 124. 
concierto del grupo Oskorri en mayo de 1976 en el barrio de la Chantrea de Pamplona. Además de las consignas antes mencionadas, un grupo del público también gritó «Nafarroa Euskadi da» [Navarra es Euskadi], colocó una ikurriña, comenzó a cantar en «Eusko gudariak» [Soldados vas$\cos ]$ hasta que se pidió dejaran de hacerlo para evitar posibles intervenciones de la Guardia Civil, mientras entre el público se sacó una pequeña bandera que llevaba escrita las siglas de la Liga Comunista Revolucionaria y ETA (VI), lo que deja patente las diferentes sensibilidades existentes entre el público asistente ${ }^{34}$.

Un efecto de esta situación fue que algunas figuras señeras de la escena musical vasca decidieran tomar un respiro y dejar de cantar. El cantante Xabier Lete se quejaba, por un lado, de que en ocasiones los organizadores intentaban presionar a los cantantes para que interpretaran canciones más «políticas» en vez de otras más «templadas» o poéticas. A lo que había que sumar, por otro lado, las interrupciones por parte del público con sus eslóganes y gritos, situación que le solía molestar, lo que no era bien recibido por el público ni por otros cantantes. Ante estas situaciones que consideraba limitaba su libertad creativa, Lete decidió dejar de cantar en público en $1978^{35}$. Igual camino siguió su esposa Lurdes Iriondo por razones similares ${ }^{36}$. Mikel Laboa, por su parte y según palabras de su mujer, también decidió tomarse un descanso en 1979 alegando, además del cansancio y otras razones, «la subordinación excesiva de los artístico a lo político que últimamente, a veces, se estaba dando» ${ }^{37}$. Laboa percibió mucho antes la intensificación del partidismo en la sociedad vasca. Su mujer menciona que ya desde 1971 había gente, alguna alejada, pero otra más cercana a su movimiento cultural, que se molestaba porque Laboa participara en conciertos como el celebrado en Paris en 1971 titulado Cinco pueblos cantan su lucha. Lo mismo le ocurrió con el Festival de los Pueblos Ibéricos celebrado en Madrid en 1976. Laboa recibió un anónimo que le acusaba de trabajar para el Partido Comunista y ser un «típico abertzale oportunista ${ }^{38}$.

Pero los efectos de esta intensificación de la vida política también se constataron en otras situaciones que se observaron en estos años. La divi-

\footnotetext{
34 Punto y Hora de Euskal Herria, 16-31.05.1976, p. 35.

35 Aristi, 1985, pp. 57 y 147, y Lete, 2011, pp. 45 y 76.

${ }^{36}$ Garaia, n. ${ }^{\circ}$ 25, 17-24.02.1977.

37 Bastida, 2014, p. 213.

38 Bastida, 2014, pp. 182 y 199.
} 
sión entre sectores más nacionalistas vascos y otros más obreristas, motejados como «españolistas», por su lucha a favor de la clase trabajadora más allá de las fronteras vascas, se hizo cada vez más radical y partidista. El cantante Gontzal Mendibil definía esta situación con un término muy clarificador: «etiketismo» ${ }^{39}$. Y a tenor de las fuentes consultadas fueron Oskorri e Imanol, representantes musicales más destacados de esta corriente de izquierdas, los que más sufrieron esta situación. Sus efectos los constataron de dos formas diferentes. Por un lado, diversas fuentes mencionan que en aquellos años se debió establecer una «lista de españolistas» y surgió una suerte de boicot a estos dos grupos. Boicot que podían desarrollar los organizadores de los conciertos, pero también los cantantes cuando imponían con quien no querían $\operatorname{cantar}^{40}$. Por otro lado, las diferencias se llevaron al campo del enfrentamiento directo contra estos cantantes. Imanol recordaba cómo en un concierto celebrado en la localidad vascofrancesa de Donibane Lohitzun (San Juan de Luz) en 1976, donde también participaba Gwendal, un grupo de gente, liderado por Telesforo Monzón, intentó sabotear el concierto con gritos como «españoles a París» ${ }^{41}$. Los integrantes de Oskorri, en ese mismo año, fueron agredidos por algunos asistentes en un concierto de la localidad vascofrancesa de Ustaritz. «[...] cuando acabábamos nuestra segunda canción, fuimos abordados y posteriormente agredidos físicamente por unas personas ajenas a la organización del festival, que no sólo se atrevieron a poner en duda nuestro patriotismo sino que incluso llegaron a arrancar la ikurriña bajo cuya sombra cantábamos, adueñándose de este modo de nuestro símbolo nacional». Hechos que interpretaban los miembros del grupo como un intento de «división entre sectores populares de Euskal Herria ${ }^{42}$. Pero las situaciones más tensas las menciona Natxo de Felipe, cantante de este grupo, en una entrevista de 2013: sufrieron dos intentos de atentado en otros tantos conciertos. En el primero, un antiguo miembro del grupo integrado en ETA les avisó que había oído el rumor de que les iban a hacer un atentado en Oiartzun. Y en el segundo de ellos, en una pequeña localidad guipuzcoana, como la organización del evento no atendió a la consigna de suspender el concierto, se puso un «petardo» debajo del escenario. Al tener que cambiarse el escenario de

\footnotetext{
39 Punto y Hora de Euskal Herria, 17-23.03.1977, p. 35.

40 Aristi, 1985, pp. 95-97, y López Aguirre, 2011, pp. 102-103.

41 Aristi, 1985, p. 96.

42 Punto y Hora de Euskal Herria, 1-15.10.1976, p. 41.
} 
lugar por la lluvia, no se hizo explotar la bomba. Circunstancia que no impidió que un grupo de jóvenes saboteara su concierto cantando "iQue viva España!» ${ }^{43}$.

\section{Los años ochenta: punk y rock radical}

El final de la década de los años setenta trajo consigo un cambio en el desarrollo de la música vasca. Supuso el principio del fin de los kantaldis, marcados más por la política casi que por la propia música, como varias voces de la época señalaban. En la revista Zeruko Argia, en 1978, al hacer un repaso sobre el año musical señalaba que la Euskal Kantagintza no había conocido grandes desarrollos en dicho año. «[...] lehengo jaialdi "politizatu" eta panfleteroen ondoren, barealdi bat iritzi dela dirudi. Ea hori kalitatezko zerbaitekin betetzen den ${ }^{44}$. Incluso miembros tan destacados de la escena musical vasca como Mikel Laboa, Benito Lertxundi o Joxean Artze, de nuevo en 1978, criticaban y renegaban de esa excesiva implicación de muchos cantantes con la política y el recurso a la canción fácil, dando al público lo que quería escuchar para sacarle su aplauso ${ }^{45}$. Parecía, por tanto, que con el cambio de década acababa una fase y se estaba dando también un cambio en los gustos musicales de la juventud vasca. Así lo señalaba el título de un artículo aparecido en el diario Egin: «Ahitu egin dira kantaldiak» ${ }^{46}$.

Los años ochenta fueron tanto años de grandes transformaciones como de graves problemas en el País Vasco. Si bien el nuevo régimen democrático se estaba estableciendo, la vida política vasca seguía siendo intensa. El recurso a la violencia de diferentes organizaciones (ETA, Comandos Autónomos Anticapitalistas, GAL...), la movilización social y la presencia policial en las calles, el intenso movimiento asociativo (desde el ecologismo, movimiento antinuclear, insumisión... hasta la ocupación, ra-

43 Berria, 5.04.2013.

44 Después de los conciertos «politizados»y panfleteros parece que ha llegado la calma. A ver si eso se llena con algo de calidad. [Traducción del autor] Zeruko Argia, n. ${ }^{\circ} 814,31.12 .1978$, p. 33 .

45 Trecet y Moreno, 1978, pp. 179, 192-193, 199, 234 у 239-240.

46 Se han acabado los kantaldis o conciertos de música vasca [Traducción del autor] Egin, 14.11.1983, p. 29. 
dios libres o fanzines ${ }^{47}$ ) o la institucionalización de la política (elecciones, partidos políticos, parlamentos...) fueron algunas características importantes de estos años, todo ello aderezado por la crisis económica y unas altas tasas de paro, especialmente juvenil. En este contexto, otro de los aspectos que indicaba que las cosas estaban cambiando fue la extensión de diversos estilos musicales entre los jóvenes vascos que aparecen unidos no sólo a estéticas específicas sino en algunos casos a estilos de vida bien diferenciados. Entre ellos, fue el punk uno de los nuevos movimientos musicales más destacados en el País Vasco durante los años ochenta.

Desde los sitios más afectados por la crisis económica y reconversión industrial, es decir, la desembocadura del Nervión, entraron en escena los conocidos grupos Zarama y Eskorbuto, entre otros. A pesar de vivir en uno de los sitios menos euskaldunes del País Vasco, Zarama fue el primer grupo de punk-rock que cantó en euskera. Eskorbuto, por su parte, fue el más claro exponente del punk vasco. En Gipuzkoa, en torno a Irun y Errenteria, surgieron los grupos Kortatu, Vomito, Basura y Odio, entre otros muchos. En Arrasate (Mondragón), pueblo del interior de la provincia, surgieron Cirrosis, RIP, Vioch-R y Puñetazo. En Araba, en Gasteiz, surgieron Hertzainak, otro de los pocos grupos que cantaban únicamente en euskera desde un inicio, y Cicatriz, liderados por Natxo Etxebarrieta, sobrino de Txabi Etxebarrieta, primer militante de ETA muerto en enfrentamiento con la policía. También se creó el conocido grupo La Polla Records en la localidad alavesa de Agurain (Salvatierra). En Navarra surgieron los Barricada, de derroteros más rockeros y heavys. A esta primera oleada de grupos le siguió, casi paralelamente, otra que extendió la formación de grupos de actitud punk, se puede decir, por todos los municipios vascos ${ }^{48}$.

Se menciona «actitud punk» porque estilísticamente todos estos grupos no solo seguían este estilo musical. Eran grupos abiertos a otras influencias musicales que llegaban a través de discos de importación, las radios libres o los viajes de muchos jóvenes al Reino Unido y otros países europeos donde conocían de primera mano otros estilos. Además del punk, estilos como el reggae, el ska, la música skin $O i !^{49}$, el hard core o

47 Para un acercamiento a este tema en Pascual, 1996 y López Romo, 2011.

48 Para el caso de Bizkaia, por ejemplo, consultar Fernández Azkarai, 2018.

49 A finales de los años setenta y principios del siguiente surgió en Gran Bretaña una segunda oleada de grupos de punk conocidos como street punk, real punk u Oi!. A los sonidos skinheads limitados hasta ese momento a ritmos jamaicanos como el reggae, ska o el rocksteady, se le fusionaron estilos británicos como el punk, pub rock o el glam. La inci- 
el heavy fueron también muy influyentes entre este amplio colectivo musical. Por tanto, más que copiar un estilo punk muy marcado, recogían esa actitud característica de los grupos de este estilo más clásicos de juntarse y con los instrumentos a su alcance, sin una formación musical previa en muchos casos, componer sus canciones para expresar sus emociones e inquietudes sociales, políticas, etc. ante un público ávido de la experiencia colectiva de los conciertos. Quizás por ello, la etiqueta que más éxito ha tenido para definir a este movimiento musical (a pesar de que muchos de los grupos concernidos no la aceptaran) ha sido la del RRV, publicado por primera vez en octubre de 1983 en el contexto de la organización de un concierto anti-OTAN en Tudela. En las páginas del diario Egin se publicó un manifiesto justificando la pertinencia de esa denominación para definir al movimiento musical surgido en el contexto socioeconómico vasco, unido a las reivindicaciones sociales y políticas de la época y caracterizado por su radicalidad en sus aspectos «musical, ya sea por los caminos del punk o del heavy más fiero, de imagen, posturas y letras» ${ }^{50}$. O como afirmaban los impulsores de esta etiqueta en una entrevista en el fanzine Muskaria, esa denominación se debía a que era «un rock muy fuerte, era radical y vasco» ${ }^{51}$.

El objetivo de este apartado es profundizar en el análisis de por qué este movimiento musical juvenil, mayormente, se acercó a ámbito político de la Izquierda Abertzale a inicios de la década de los ochenta ${ }^{52}$. Para ello se intenta ir algo más allá de la propia constatación de este proceso, de la explicación que considera que la confluencia con el mundo de Herri Batasuna (HB) se produjo rápidamente y sin dificultades, casi «naturalmente», por el carácter rupturista y antisistema de ambas partes ${ }^{53}$ o de la visión que proporcionan varios de los participantes en aquel movimiento. Según ésta última, el entorno de HB intentó encauzar a este movimiento musical pujante

dencia de este estilo fue importante en la escena musical vasca. La primera referencia de este estilo musical en el País Vasco surgía en Irun en el año 1981 con la banda que mejor representaba el movimiento Oi! y skinhead del momento, Kortatu. El segundo punto central de esta escena lo encontramos en Arrasate, que se convirtió en centro neurálgico de este movimiento, con grupos como los citados más arriba.

${ }^{50}$ Egin, 16.10.1983, p. 25.

51 Muskaria, n. ${ }^{\circ}$ 19, nov.-dic. de 1983, p. 13. [Se utiliza la edición facsímil de esta revista reeditada por el colectivo Banizu Nizuke en el año 2010]. Un acercamiento a este movimiento musical publicado recientemente en Del Amo, 2016.

52 Un reciente e interesante estudio sobre este tema en Mota, 2017.

53 Sánchez Ekiza, 2013, p. 48, y Del Amo, 2016, pp. 78 y ss. 
para sus intereses políticos y electorales, mientras los grupos musicales consiguieron a cambio una atención a sus necesidades y una plataforma para celebrar conciertos por todo el País Vasco ${ }^{54}$. Sin negar la validez de estos planteamientos, en este trabajo se intenta situar este proceso en un contexto más amplio y relacionarlo con otra serie de factores que también, se considera, habría que tomar en consideración para explicar esta situación.

No parece que la convergencia mencionada fuera un proceso «automático». El movimiento punk no fue inicialmente aceptado por muchos sectores sociales y políticos vascos, ni siquiera dentro del ámbito de HB. Para muchos nacionalistas vascos este movimiento punk no representaba adecuadamente a lo «vasco». En primer lugar, el estilo musical era importado del mundo anglosajón y no estaba conectada con las tradiciones musicales vascas. El cantante del grupo Zarama criticaba que muchos considerasen el rock como enemigo del folklore lo que provocaba una suerte de incomprensión, sino rechazo, de este movimiento ${ }^{55}$. El rock era para muchos, en definitiva, un «producto más del imperialismo multinacional yankee» ${ }^{56}$. Todavía en 1984 algunos autores diferenciaban entre la música vasca recién creada, cuya característica definitoria sería el rock y las influencias foráneas, frente a la música tradicional vasca, según esta visión, la de «siempre», la que estaba unida con la identidad vasca ${ }^{57}$. Llegándose incluso a señalar que durante la campaña de Martxa eta borroka [Marcha y lucha] de HB de 1985, que puede considerarse como el punto culminante de acercamiento mencionado, se siguió debatiendo sobre este tema entre sus organizadores $^{58}$. En segundo lugar, muchos de estos iniciales grupos punk cantaban en castellano, lo que, atendiendo a lo señalado para el periodo anterior, suponía una contradicción con todo el movimiento nacionalista y musical del Euskal Kantagintza Berria. En tercer lugar, la relación de esta juventud con las drogas era otra característica que el entorno de HB consideraba negativamente ${ }^{59}$. Durante estos años, para la juventud contestataria

54 Blasco, 1987, pp. 21-22.

55 Muskaria, n. ${ }^{\circ}$ 1, en.-feb. de 1980, p. 8. Reflexiones en este sentido de los propios protagonistas de estos grupos se puede encontrar en el documental Salda Badago, los inicios del rock vasco de 2002 [https://www.youtube.com/watch?v=grgfeAdXStQ consultado 01.09.2017].

56 Blasco, 1987, p. 17.

57 Egin, 15.01.1984, p. 19.

58 Herri Batasuna, 1999, p. 162.

59 Así lo destacaban, por ejemplo, los integrantes del grupo Kortatu (Herreros y López, 2014, pp. 130-132). 
una de las parcelas que deseaban desarrollar como forma de expresión de su libertad personal y para demostrar su carácter rebelde e inconformista era el uso y disfrute de las drogas. En un contexto de desinformación sobre los efectos de muchas de ellas, la heroína causó una verdadera crisis social por el impacto que causó entre muchos jóvenes de la época. Esta visión sobre las drogas chocaba con el discurso contrario a su consumo difundido por la Izquierda Abertzale, que las consideraba una estrategia del Estado para «adormilar» a la juventud, siendo, en consecuencia, otra forma de represión. En definitiva, la droga estaba al «servicio de la burguesía imperialista y de las oligarquías en el poder» para manipular, desorientar y desviar de sus propios intereses a la juventud ${ }^{60}$. Y el reflejo de esta visión fue la campaña de ETA contra los bares donde se consumía y traficaba con estas sustancias; locales que, en muchas ocasiones, eran frecuentados por estos jóvenes punk. Circunstancia que creaba sorpresa, sino fricciones, entre esta organización política y estos jóvenes ${ }^{61}$. En cuarto lugar, también creaba cierto ambiente contrario a este movimiento musical la visión que sobre su comportamiento en las calles podían tener otros sectores sociales. Su comportamiento «disruptivo» y contrario a las normas sociales, el consumo de drogas en público, la idea del rular por las calles ${ }^{62}$ o el propio comportamiento en los conciertos (el baile pogo, la actitud frente a los grupos musicales, el lanzamiento de objetos, etc.) hacía que muchas personas tuvieran bastante prevención sobre estos jóvenes.

Pero, quizás, otro aspecto que pudiera haber dificultado el proceso de acercamiento al mundo de HB de este movimiento musical se puede relacionar con la visión política de estos sectores juveniles. Si se atiende a su componente sociopolítico, se puede decir que se basa en una oposición radical o una «negación punk» del sistema social en el que vivían los jóvenes, así como de sus valores, cuya máxima expresión podría ser el «anti-todo»63. Como se mencionaba en un temprano artículo sobre el punk británico, «los Punks se ríen de todos y de todo, se desesperan por el presente, no creen en el futuro y odian la sociedad de consumo y todo lo que ella representa» ${ }^{64}$. Pero esta actitud «anti-todo» adquirió una re-

${ }^{60}$ Fragmento de un artículo de Manolo Blanco Chivite en Punto y Hora de Euskal Herria, n. $209,15-22.01 .1981$.

61 Arriola, 2016, p. 267 y ss., y Moso, 2004, p. 49.

62 Porrah, 2006, pp. 343-344.

63 Porrah, 2006, p. 24

${ }^{64}$ Egin, 26.11.1977, p. 17. 
levancia social destacada en el País Vasco por aparecer unida a un contexto político y económico convulso y con una alta movilización social. Algún integrante de este movimiento musical ha señalado su composición heterogénea y su poca ortodoxia interna, las muchas dudas y debates entre sus integrantes, atendiendo a la variedad de gente e ideas de las personas que lo conformaban ${ }^{65}$. A pesar de ello, siguiendo al sociólogo Jakue Pascual, el punk vasco partía de un discurso de negación al sistema pero cuando sus integrantes reflexionaron sobre posibles alternativas lo hicieron en el ámbito de los «planteamientos político-sociales e ideológicos autónomos (no partidistas)» ${ }^{66}$. Era un movimiento caracterizado, en definitiva, por el asamblearismo, una organización de base horizontal y la autonomía, cercano a corrientes libertarias, que rechazaba el dirigismo vanguardista que algunas organizaciones políticas deseaban desarrollar ${ }^{67}$. En ese sentido, este movimiento confluyó en un entorno político amplio coincidente con la Izquierda Abertzale, los partidos de izquierda revolucionaria y el movimiento antiautoritario anarquista ${ }^{68}$.

A pesar de estas características que se acaban de mencionar, que en un principio pudieran llevarnos a considerar que dificultaban el acercamiento al mundo de la Izquierda Abertzale del movimiento punk, no impidió que se diera este proceso dentro de la campaña de Martxa eta borroka del año 1985. Unos años antes, desde principios de los años ochenta, las fiestas patronales también se convirtieron en un ámbito para desarrollar actividades reivindicativas y propagandísticas. La campaña Jaiak bai, borroka ere bai [Fiestas sí, lucha también] supuso un primer paso en ese sentido ${ }^{69}$. Este proceso se intensificó en 1985 cuando desde HB se propuso la campaña Euskadi, alaitsu eta borrokan kementsu [Euskadi alegre y combativa]. Campaña compuesta por multitud de actos reivindicativos y, mayormente, culturales (debates, cine, exposiciones, comidas populares, etc.) organizados por todo el País Vasco. Con ello se buscaba dar a entender que la acción de este partido político no sólo estaba unida a los aspectos dramáticos y luctuosos de la vida polí-

65 Moso, 2004, p. 108.

66 Pascual, 2011, p. 69.

67 Ideas anarquistas que también influyeron en las visones sobre la idea de nación entre algunos de estos grupos, aspecto analizado con más detalle en Porrah, 2006, pp. 186187, y Saenz del Castillo, 2016, pp. 300-309.

68 Pascual, 2011, pp. 66-72.

${ }^{69}$ Punto y Hora de Euskal Herria, n. ${ }^{\circ}$ 292, 31.12.1983-7.01.1984, p. 24. 
tica vasca de aquellos años, sino que también estaba presente en otras esferas de la vida social ${ }^{70}$.

En todas estas campañas, uno de los pilares de las actividades desarrolladas fueron los festivales musicales, de diferentes estilos, pero entre los cuales los conciertos de grupos encuadrados en el RRV pasaron a ocupar un lugar destacado. El primer paso desde el mundo de la Izquierda Abertzale para acoger a este movimiento musical, que todavía estaba dando sus primeros pasos, fue el concurso Eginrock organizado por el periódico del mismo nombre, más bien por su suplemento musical Plaka Klik, a finales de 1983. Se trataba de un concurso para elegir a los mejores grupos por cada una de las provincias vascas y organizar un concierto con los ganadores elegidos por los lectores del periódico, celebrado en enero del siguiente año en Vitoria ${ }^{71}$. Aunque en un principio se trataba de una actividad para conectar el periódico con el público joven, se pudo observar el éxito de asistencia e impacto del mismo ${ }^{72}$. Éxito que trajo aparejado que en la campaña electoral de las elecciones autonómicas de febrero de 1984 varios grupos del RRV actuaron en mítines de $\mathrm{HB}^{73}$. Pero el verdadero salto adelante en este proceso fue en 1985, dentro de la campaña Euskadi, alaitsu eta borrokan kementsu. Dentro de las actividades de esta campaña, uno de sus ámbitos de trabajo fueron los festivales musicales organizados bajo el título Martxa eta borroka. En estos festivales, organizados por todo el territorio entre los meses de febrero y marzo de ese año, muchos de los grupos del RRV mencionados más arriba, y otros, tuvieron la oportunidad para actuar. El cierre de la campaña fue un concierto multitudinario celebrado en Bilbao el 23 de marzo, con la actuación, entre otros, de Zarama, Kortatu, La Polla Records o Barricada ${ }^{74}$.

La campaña Martxa eta borroka fue el momento en el que muchos grupos musicales de los estilos mencionados apareció más unido con el mundo de la Izquierda Abertzale, identificación que se mantuvo el resto

70 Herri Batasuna, 1999, pp. 161-163. Egin, 16.02.1985, p. 7, 1.03.1985, p. 7, 22.03.1985, p. 6, y 25.03.1985, pp. 19-26. Punto y Hora de Euskal Herria, n. ${ }^{\circ} 381$, 01.03.1985, pp. 11-12.

71 Egin, 23.10.1983, p. 24 y 29.12.1983, p. 21.

72 Egin, 24.01.1984, p. 21.

${ }^{73}$ Egin, 19.02.1984, p. 22. En el caso de Hertzainak y Klabelin Komik también lo hicieron en un mitin de la fuerza de izquierda nacionalista y revolucionaria Auzolan (Egin, 22.02.1984, p. 6).

${ }^{74}$ Egin, 22.03.1985, p. 6, y 25.03.1985, pp. 19-26. 
de la década de los ochenta y más adelante. En este apartado se busca aportar una serie de factores que nos ayuden a entender qué elementos del contexto de aquellos años explican este proceso. Pero, antes de ello, es necesario mencionar previamente que este acercamiento no se produjo de forma homogénea. No todos los grupos musicales encuadrados dentro de la etiqueta del RRV se integraron directamente en el entorno político de HB. Fue Eskorbuto el grupo que más claramente mostró su rechazo a esta vinculación ${ }^{75}$. El grupo alavés Cicatriz, en boca de su cantante Natxo, también manifestó sus reservas a los intentos de controlar a la juventud a través de la organización de conciertos y calificó la campaña Martxa eta Borroka como una forma de conseguir los votos de los jóvenes ${ }^{76}$. Otros grupos también mantuvieron esta actitud crítica, como Odio, que aun viendo bien la actitud de HB para «abrir los ojos» de la gente ante la situación del país, rechazaban cualquier tipo de manipulación política ${ }^{77}$. El grupo de Errenteria Basura, por su parte, se negaba a aceptar la integración en ninguna organización política, ni siquiera $\mathrm{HB}^{78}$. Los integrantes del grupo Zarama, aun reconociendo su cercanía a un genérico ámbito de izquierdas y nacionalista vasco, rechazaban identificarse con ninguna sigla en concreto y criticaban el sectarismo que se observaba entre las organizaciones de ese ámbito ${ }^{79}$. Incluso los organizadores en Araba de la campaña Martxa eta borroka reconocían que los grupos más importantes de esta provincia «eran casi en su totalidad autónomos o del entorno de $L K I{ }^{80}$. Así, Josu Zabala, integrante del grupo Hertzainak, reconocía que a pesar de la cercanía a $\mathrm{HB}$, no tenían reparos en criticarla porque «eso no quiere decir que seamos como ellos ni que pensemos exactamente como ellos» ${ }^{81}$. Pero la crítica más fuerte a este intento de HB por reconducir al punk proviene del ámbito autónomo vasco, que considera al RRV como un «gran timo» porque convirtió un movimiento musical contracultural en una mercancía cultural e ideológica al servicio de la industria discográfica y «las ambiciones partidistas de Herri Batasuna» 82 .

75 Una visión sobre las relaciones entre este grupo y HB en Mota, 2016, pp. 324-328.

76 Espinosa y López, 2013, 118-119. Natxo Cicatriz amplió estas ideas en una entrevista en Muskaria, n. ${ }^{\circ}$ 28, verano de 1986, p. 26.

77 Muskaria, n. 27, abril de 1986, pp. 21-22.

78 Egin, 6.11.1983, p. 25.

79 Punto y Hora de Euskal Herria, n. ${ }^{\circ} 370,7.12 .1984$.

${ }^{80}$ Herri Batasuna, 1999, p. 163. Visión ampliada en Pascual, 2015, pp. 217-219.

81 Espinosa y López, 2013, p. 106.

82 Estebaranz, 2007, p. 26. Más opiniones en este sentido en Pascual, 2015, pp. 198-201. 
A pesar de todo lo afirmado, esta conexión entre RRV e Izquierda Abertzale sí se produjo y aquí se busca proponer una serie de factores que ayuden a comprender mejor cómo se produjo este proceso. Se trata de cuatro aspectos que se pueden considerar más como líneas de trabajo a desarrollar que como conclusiones definitivas, pero que se consideran sirven para situarlo adecuadamente.

En primer lugar, el discurso del nacionalismo revolucionario vasco fue adaptándose al nuevo contexto democrático y adquiriendo una serie de características específicas. Este entorno abandonó el fuerte dogmatismo ideológico, unido al sectarismo observado entre las diferentes organizaciones revolucionarias, que le había caracterizado en la década anterior que, como se ha afirmado, provocó la división y el agrio enfrentamiento entre las diferentes opciones de este ámbito político. Ese sectarismo era considerado la enfermedad de los revolucionarios, según un artículo de opinión publicado en Egin. Según su autor se había empleado más energía para enfrentarse entre ellos que para buscar su unión, lo que había debilitado al conjunto de este sector político. Incluso, consideraba, HB había pecado de dicha característica. Por ello proponía que ante el nuevo contexto se debían unir esas fuerzas de la izquierda revolucionaria vasca en un programa mínimo ${ }^{83}$. Aunque este no sea el lugar para desarrollar este aspecto con detalle, se puede afirmar que la propia creación de HB y la defensa de la alternativa KAS supusieron un cambio en este sentido, aunque, como se ha visto, no había supuesto la desaparición total de ese sectarismo. Con la alternativa KAS se fueron limando, sino abandonando, las diferencias ideológicas tan marcadas dentro del marxismo por un discurso más abierto y menos definido basado en el independentismo y un socialismo genérico donde diferentes sectores de ese ámbito podían tener cabida. Pero para los objetivos de este artículo interesa destacar que todo ello apareció unido a un rechazo radical de la situación que se había abierto con el inicio de la Transición y el establecimiento de la democracia. Se consideraba que la «reforma» del sistema no había supuesto un cambio real sino la posibilidad de adaptación y mantenimiento de su poder de los pilares fundamentales del Franquismo (el ejército, el capital y la Iglesia) y de muchos de sus integrantes a un nuevo periodo. Mientras, además, la aprobación de los estatutos de autonomía había supuesto la división de la nación vasca. Por todo ello, la postura de HB era de un re-

${ }^{83}$ Egin, 4.01.1984, p. 18. 
chazo radical a todo el nuevo contexto político institucional; rechazo radical que ETA llevaba un paso más allá. Frente a la «reforma» era necesaria la «ruptura». Esta reformulación programática más abierta, unida a un contexto de fuerte represión policial, posibilitó que diferentes partidos de este ámbito pudieran solicitar el voto para HB y acercarse al entorno de la Izquierda Abertzale, aunque sin perder su autonomía ${ }^{84}$.

Este discurso rupturista radical con el Estado español, en segundo lugar, conectaba con la negación radical del punk del orden social mencionado más arriba ${ }^{85}$. ¿Qué podía ser más «anti-todo» que apoyar al partido y a la organización terrorista más antisistema de aquellos años? ¿Qué podía ser más radical que aquellas organizaciones que luchaban por todos los medios contra el orden social español? El mundo de HB se convirtió en un referente de oposición al orden social que, aunque solo fuera en las elecciones, era o debía ser apoyado. Incluso entre los grupos musicales, como se ha señalado, con los que podía existir cierta contradicción entre sus opiniones o posiciones ideológicas, más cercanas a la autonomía libertaria, existía esta identificación con la Izquierda Abertzale por ser la fuerza que más se enfrentaba al sistema social ${ }^{86}$. Como se mencionaba en un artículo de Rafael Castellano en El País, la «extrema juventud radical», aun siendo anarquista o pasando de la política, votaba y lo hacía por $\mathrm{HB}^{87}$. Por tanto, no resulta extraña que muchos de los grupos del RRV participaran en campañas como la de Martxa eta borroka al aparecer unido a un entorno político que era visto con buenos ojos por muchos grupos.

En tercer lugar, desde inicios de los años ochenta hay un proceso de reorganización interna de la Izquierda Abertzale para adaptarse al nuevo contexto abierto con el nuevo periodo democrático. Para los objetivos de este artículo interesa destacar dos aspectos diferentes. Por un lado, la Izquierda Abertzale hizo un intento por acercarse a los movimientos sociales que se estaban desarrollando en los años ochenta. Como se ha afirmado, aquellos años fueron años de fuerte movilización social en di-

${ }^{84}$ Merino, 2011, pp. 135 y ss. Un estudio más detallado de este discurso radical en Mata, 1993, pp. 171 y ss.

${ }^{85}$ Del Amo, 2016, p. 80.

86 El mencionado Natxo del grupo Cicatriz, a pesar de todas sus críticas al mundo de la política, incluso la de HB, reflejaba una posición más positiva sobre este partido, sin renegar de su antipoliticismo (Muskaria, n. ${ }^{\circ} 28$, verano de 1986, p. 26). El cantante del grupo Odio, rechazando la posible manipulación de los políticos, también afirmaba estar de acuerdo con HB (Muskaria, 27, abril de 1986, pp. 21-22).

${ }^{87}$ El País, 1.12.1986. 
ferentes ámbitos. Ante esta movilización HB buscó los medios de intentar convertirse en su referente y portavoz, con el claro objetivo de acercarlos o integrarlos a su seno. Para ello los concejales de este partido se atribuyeron la defensa de estas reivindicaciones sociales en los ayuntamientos $\mathrm{o}$, en otras ocasiones, intentaron liderar movimientos como el antinuclear, pro-amnistía, etc. Entre estos ámbitos de actuación de HB se destacan dos. Los militantes de este entorno intentaron controlar las comisiones de fiestas de los ayuntamientos para hacerlas «auténticamente participativas y abiert[a]s a las capas populares». Así, «Desde los ayuntamientos y la calle los militantes de HB son los primeros en ponerse a la cabeza de la organización de fiestas y de dotarlas del justo tono crítico y reivindicativo». HB, además, buscó secundar todas las iniciativas sociales locales entre las que se señalaba expresamente a las asambleas de jóvenes que se fueron creando en muchos municipios para exigir locales para desarrollar sus actividades de ocio de forma autogestionada ${ }^{88}$. Estos dos ámbitos fueron importantes porque, en muchas ocasiones, quedó en sus manos la organización de conciertos en el País Vasco.

Por otro lado, desde la Izquierda Abertzale su buscó intensificar la labor entre la juventud vasca con la intención de atraerla a su entorno, para lo cual fue la organización juvenil Jarrai la que comenzó a reflexionar sobre cómo desarrollar esa labor. Si bien esta organización juvenil se había creado en 1979, no parece que había adquirido el papel importante que se le pretendía conferir. Quizás fuera porque se hubiera limitado a ejercer de correa de transmisión de las decisiones de los dirigentes de HB a sus jóvenes militantes, a inicios de los años ochenta se comienza a constatar que no estaban consiguiendo atraer a la juventud vasca en un momento en el que esta aparecía especialmente movilizada y sus votos se hacían cada vez más necesarios. La juventud «pasota» que no votaba o que «cuando tu vecino de veinte años te dice que por favor no seas muermo y no le mamonees con la política y que pasa de los vasquetas» dejaban bien a las claras que había que trabajar con esta juventud con otros medios. Había que acercarse a ellos, en los pueblos y barrios, para desarrollar una importante labor de «ideologización» ${ }^{89}$. Estos fueron algunos de los planteamientos que se trataron en el II Congreso de Jarrai celebrado en 1983. De entre los diferentes temas que se discutieron en ese congreso estuvo la idea

88 Egin, 24.02.1984, p. 23.
${ }^{89}$ Egin, 10.01.1984, p. 19.

Historia Contemporánea 57, 2018: 377-412 
de que Jarrai debía trabajar por su programa político de forma más constante y estar presente, tanto de forma individual o como organización, en todas las reivindicaciones específicas que surgían entre la juventud vasca, más allá de la propia reivindicación nacional que la había dominado hasta entonces. Con ello se buscaba atraer a la juventud que «pasaba» de la política, para lo cual era necesario integrarse en las asambleas locales de jóvenes como primer paso, aportando gente entregada a esos movimientos y convirtiéndose en cabeza visible de los mismos, más que establecer desde «arriba» una estructura organizativa para los jóvenes ${ }^{90}$.

Uno de los colectivos juveniles a los que se pretendía atender era al de los jóvenes punk, heavies, etc., donde habitualmente se consideraba anidaba el pasotismo. Se destacaba que muchos de estos jóvenes vivían una situación dura y tenían un futuro difícil, circunstancia por la que sus intereses y los de Jarrai eran similares. Y por la que se debía buscar una propuesta colectiva para este colectivo y atraerlos a la Izquierda Abertza$1 \mathrm{e}^{91}$. Y si se pretendía atraer a la juventud vasca más comprometida al entorno de HB, eso no se podía hacer dejando de lado al RRV, cuyos textos comprometidos le conectaban con el movimiento independentista ${ }^{92}$. Por ello, la mayor predisposición a la juventud más movilizada se reflejó en la organización de conciertos de grupos del RRV, como quedo en evidencia desde la misma clausura del congreso de Jarrai en el que intervinieron Hertzainak, Akelarre e Itoiz ${ }^{93}$. O en el concierto Eginrock de finales de 1983, donde los integrantes de esta organización juvenil pusieron una pancarta con el lema de su congreso: sin juventud no hay revolución ${ }^{94}$. Proceso que se intensificó en las campañas antes mencionadas y en los conciertos organizados por las asambleas de jóvenes y las comisiones de fiestas por todo el País Vasco.

En cuarto lugar, se puede añadir otra explicación para comprender la vinculación de muchos grupos musicales que se podrían situar detrás de la etiqueta del RRV con la Izquierda Abertzale. Si bien en el caso de algunos grupos se ha observado una actitud crítica a este entorno político,

90 Punto y Hora de Euskal Herria, n. $.^{\circ} 314,17-24.06 .1983$, pp. 18-23, n. ${ }^{\circ} 332$, 1623.12.1983, pp. 20-21, y n. ${ }^{\circ} 349,27.04-4.05 .1984$, pp. 31-32.

91 Punto y Hora de Euskal Herria, n. ${ }^{\circ} 314,17-24.06 .1983$, pp. 18-23, y n. ${ }^{\circ} 349,27.04-$ 4.05.1984, pp. 31-32.

92 Herri Batasuna, 1999, p. 161.

${ }_{93}$ Egin, 7.12.1983, p. 5.

94 Punto y Hora de Euskal Herria, n. ${ }^{\circ} 337,27.01-03.02 .1984$, p. 23. 
otros muchos fueron militantes o seguidores declarados del mismo. Por tanto, no resulta extraña esta cercanía y que en muchas de sus canciones y letras se observara la conexión con el mismo ${ }^{95}$. Quizás se pueda considerar al grupo de Irun Kortatu como uno de los más claros exponentes de esta idea. Desde joven su líder Fermín Muguruza había militado en $J a$ rrai, aunque por divergencias internas en torno al uso de las drogas se distanció de esta organización. Si bien su cercanía a la Izquierda Abertzale no desapareció en ningún momento, su compromiso se reforzó cuando fue testigo de un atentado de los GAL en el Hotel Monbar de Baiona. Al preguntarle a Fermin Muguruza por Martxa eta borroka, éste afirmaba que «Era un proyecto social que estaba ahí y Herri Batasuna lo puso en contacto, porque faltaba una relación orgánica. Nosotros claramente apoyábamos este movimiento y siempre estaremos con esa gente. Había nuevos valores y además aquellas épocas había polémicas muy grandes, nosotros estábamos a favor de la insumisión, Jarrai y HASI no, pero si ASK que estaba dentro de KAS... pero, aparte de todo eso, nos pareció interesante tener esa relación, fue un paso valiente» ${ }^{96}$. Fueron sus conciertos en la campaña Martxa eta borroka, así como su declarada cercanía a HB manifestada directamente o en varias de sus letras, los que le dieron un espaldarazo importante a este grupo, además de su indudable valía musi$\mathrm{cal}^{97}$. Espaldarazo que sirvió para observar la importancia que podían tener estos grupos como medio de difusión de ideas y actitudes cercanas al mundo del nacionalismo radical, además de proporcionarle una «banda sonora» y dimensión cultural nueva que conectaba con las generaciones

95 En este apartado no se pretende realizar un estudio detallado de los diferentes grupos y sus composiciones que podrían situarse en esta posición, labor que extendería excesivamente este artículo, sino presentar un proceso general que también ha sido mencionado en trabajos como Lahusen, 1993, pp. 273-278 y Dávila y Amezaga, 2003-2004, pp. 226-227 o en un artículo de Punto y Hora de Euskal Herria (agosto de 1986, p. 16). Como ejemplo de lo afirmado puede servir la entrevista realizada al grupo alavés Danba en 1987, en la que mostraban claramente su ideología política al señalar que «Nunca nos hemos proclamado anarquistas [...] Aquí arriba, es decir, en Euskal Herria, tenemos que conseguir la independencia y el socialismo, y luchamos por eso [...]. La soberanía y la autodeterminación de Euskal Herria, proponemos todo esto, porque con esto estamos totalmente identificados» [Traducción del autor] (Muskaria, n. ${ }^{\circ}$ 28, verano de 1986, p. 34).

${ }^{96}$ Fanzine Zarata, n. ${ }^{\circ}$ 4, Número especial «Kaskamotzak 80. hamarkadako Euskal Herrian», p. 33 .

97 Herreros y López, 2014, pp. 113-114, 130-131 y 137-138, Blasco, 1987, p. 21, y Punto y Hora de Euskal Herria, monográfico, abril de 1988, p. 62. Blasco, 1987, p. 21. 
más jóvenes ${ }^{98}$. De hecho, el periodista Pablo Cabeza, gran conocedor de este movimiento musical, destacaba en 1986 la importancia de Kortatu en la aceptación de HB de este estilo de música: «Su claro y rotundo posicionamiento abertzale ha logrado, mayormente, que este tipo de música no se vea como cultura enemiga. ¡Cómo lo va a ser si la utiliza como útil de expresión un trío de claro nacionalismo!»99

A partir de 1987 se comenzaron a escuchar diferentes voces que rechazaban la etiqueta de RRV, incluso de algunos grupos destacados de este ámbito. Incluso Pablo Cabeza, uno de sus impulsores, llegó a preguntarse si era el fin del RRV ${ }^{100}$. Sin embargo, esta circunstancia no supuso ningún problema para el proceso que se acaba de mencionar. El siguiente dato refleja bien el aspecto que se está analizando y cómo dicho proceso se intensificó a partir de 1985: el integrante del grupo Hertzainak, Josu Zabala, mencionaba en 1993 que el setenta por ciento de los conciertos que se organizaban en esos años se montaban en torno a HB; dato que refleja esta conexión apuntada ${ }^{101}$.

\section{Conclusiones}

Como se puede desprender de la lectura de este artículo, su objetivo ha sido presentar la evolución de la relación entre vida política y música popular en el País Vasco en un periodo de grandes cambios. Descripción en la que se han ido buscando respuestas sobre los procesos que se han observado a lo largo del periodo estudiado. Pero, en todo caso, la evolución presentada hay que entenderla más que como unas conclusiones definitivas, como una proposición de líneas de investigación para el futuro, todo ello con el objetivo de continuar profundizando en el estudio de la vida política vasca de estos años. Y para ello, se considera que el estudio de la música popular y la juventud aporta un campo de estudio fructífero porque permite adentrarse en el estudio de un ámbito de la política no tan estudiado, las formas cotidianas de acción política.

98 Del Amo, 2016, p. 87.

99 Punto y Hora de Euskal Herria, monográfico, agosto de 1986, p. 20.

100 Punto y Hora de Euskal Herria, n. ${ }^{\circ}$ 541, 23.02-5.03.1989, p. 53. Otras ideas en este sentido en Herreros y López, 2013, pp. 148-154.

101 Espinosa y López, 2013, p. 82. 
Es sobradamente conocido que la música, desde hace bastantes décadas, quizás desde principios del siglo Xx, juega un papel importante en la vida de los jóvenes, tanto desde el punto de vista lúdico como por suponer una forma de conformación y expresión de su identidad ${ }^{102}$. En este caso se ha destacado el importante papel político que podía jugar entre los jóvenes y para comprobarlo se ha elegido un periodo políticamente convulso. En esta investigación se ha constatado, por un lado, que las canciones y sus letras podían servir como forma de difusión de ideas de carácter político entre los jóvenes. Durante el Franquismo, mayormente, de una forma más simbólica o metafórica, por las dificultades que la censura del régimen imponía a todas las manifestaciones culturales y que los cantantes intentaban sortear. Incluso el mero hecho de cantar en euskera ya era un posicionamiento político en aquellos años finales del régimen. Desde la Transición en adelante, los planteamientos políticos presentes en muchas canciones pudieron ser más explícitos gracias al periodo de libertades que se estaban estableciendo. Las letras radicales de los grupos punk son un buen ejemplo de ello. Por todo ello, su función como ámbito de difusión de ideas y planteamientos políticos, unido mayormente al ámbito del nacionalismo vasco, fue clave durante este periodo. Se considera que fue clave porque las canciones llegaban a más gente que los propios documentos de propaganda de los partidos políticos o los sesudos textos de los ideólogos de esas formaciones.

La música popular, por otro lado, jugó un papel importante como forma de expresión política de los jóvenes durante estas décadas. En el marco temporal elegido, la música y los conciertos se convirtieron en un aspecto relevante para la juventud vasca, por servir como ámbito a través del cual presentar su disconformidad con la situación que les tocaba vivir y expresar sus planteamientos políticos. Durante los últimos años del Franquismo los conciertos eran una válvula de escape para el malestar político existente en la sociedad vasca en el contexto represivo del régimen dictatorial, además de servir como punto de encuentro de sectores sociales más amplios en el entorno del antifranquismo. La sola asistencia a los conciertos unía e identificaba a los asistentes con la lucha contra el régimen franquista que representaba cualquier ámbito que buscara defender la cultura vasca. Con el paso de los años, los conciertos se fueron convirtiendo cada vez más en momentos donde los planteamientos políticos y la

102 Turino, 2008, pp. 93 y ss. 
propaganda política se hicieron más presentes y más explícitos. Y durante los años ochenta, fue el momento en el que los discursos más radicales y contrarios al orden social «inundaron» los conciertos. En ambos momentos la música fue un canal de expresión política, sobre todo cercana al ámbito del nacionalismo vasco. Aunque esta característica general no impida observar que existían diferentes ámbitos ideológicos (izquierda revolucionaria o anarquismo) que también se vieron reflejados en el ámbito de la música.

Si la música popular era tan importante en la vida política de los jóvenes de estos años, no resulta extraño que las diferentes organizaciones políticas intentaran acercar a su seno a los músicos o que los quisieran «utilizar» para difundir sus postulados a la población vasca. La relación entre ambas esferas fue doble. Por un lado, como se acaba de mencionar, los cantautores y grupos musicales influyeron en la vida política al convertirse en destacados medios de difusión y expresión de ideas políticas. Pero, por otro lado, el contexto político y las diferentes organizaciones políticas también influenciaron (o lo intentaron) en el desarrollo de esos movimientos musicales dando más cancha a algunos grupos o desarrollando una destacada labor de organización de conciertos. Labor, esta última, importante en la década de los ochenta toda vez que no había un tejido de salas de conciertos privados donde los grupos pudieran actuar. Se ha podido observar esta proyección de las organizaciones políticas en la actividad musical con diferentes ejemplos. Situaciones que pasaban desde pedir canciones más comprometidas a los cantantes, organizar conciertos donde, según algunas fuentes, se excluía a algunos cantantes, hasta organizar conciertos en los mítines electorales o campañas de propaganda de los partidos.

Sin embargo, antes de finalizar este artículo, resulta conveniente matizar esta conexión entre política y música popular en el País Vasco. La confluencia con y la posible «instrumentalización» de estos movimientos musicales por diferentes organizaciones políticas no debe esconder la variedad de situaciones vividas por estos solistas y grupos musicales. Si muchos manifestaron su clara vinculación con diferentes opciones políticas organizadas, otros intentaron mantener su autonomía artística, lo que no implica que carecieran de una visión política sobre la sociedad vasca. Dilucidar este aspecto requeriría un estudio detallado y pormenorizado de estos cantantes y grupos. Pero esta matización también se podría llevar más allá de los estilos musicales estudiados en este trabajo; estilos, sin duda, menos masivos y que muchas veces pasan desapercibidos, pero que 
también tenían su público. Los conciertos, por su parte, eran, como se ha afirmado, momentos expresión personal y directa de muchos de los planteamientos políticos presentes en la juventud vasca de aquellos años. Pero ello no debe llevarnos a considerar que fue toda la juventud vasca la que siguió los derroteros marcados por el análisis realizado en este artículo. Mucha juventud no se acercó a estos conciertos y estilos musicales; otros muchos se acercaron a los conciertos con una finalidad lúdica (p.ej., cuando se celebraban dentro de las fiestas patronales locales), pero sin identificarse totalmente con los postulados ideológicos expresados por los cantantes y grupos, o parte del público asistente a los conciertos cuando exteriorizaba sus planteamientos políticos u otro tipo de consignas. Esta matización debe llevarnos a evitar considerar el todo por la parte cuando analizamos la música popular en este periodo.

Aun así, se puede concluir que la música popular formaba parte de la vida de los jóvenes. La diversión, el ocio, los diferentes gustos musicales o las formas de vida juveniles eran elementos importantes entre la juventud vasca. Pero el contexto social y político de aquellos años, a su vez, también afectaba e impregnaba el vivir diario de la juventud y a sus percepciones sobre la sociedad en la que vivían. El contexto vasco de las décadas estudiadas posibilitó que confluyeran la música popular, la juventud y la política y que se creara una suerte de amalgama o tupida escena musical interconectada con la política vasca de aquellos años en la que era difícil diferenciar las diferentes esferas.

\section{Bibliografía}

ARISTI, Pako, Euskal Kantagintza Berria 1961-1985, Erein, San Sebastián, 1985.

ARRIOLA, Justo, A los pies del caballo. Narcotráfico, heroína y contrainsurgencia en Euskal Herria,Txalaparta, Tafalla, 2016.

ARTZE, J.A., «Kanta berria aztertzen», Jakin, n. ${ }^{\circ}$ 4, 1977, pp. 45-50.

Ballinger, R., «Politics», en Horner, B. y Swiss, T. (eds.), Key terms in popular music and culture, Blackwell, Oxford, 1999, pp. 57-70.

BASTIDA, Marisol, Memorias. Una biografía de Mikel Laboa, Elkar, San Sebastián, 2014.

Blasco, Rogelio, «Nuevo rock vasco: un fenómeno sociológico», Cuadernos de Alzate, n. $^{\circ}$ 6, 1987, pp. 12-29.

DÁVILA, Paulí y AmEZAGA, Josu, «Juventud, identidad y cultura: el Rock Radical Vasco en la década de los 80», Historia de la Educación, n. ${ }^{\circ} 22-23,2003-$ 2004, pp. 213-231. 
Del Amo, Ion Andoni, Party \& Borroka. Jóvenes, música(s) y conflicto $(s)$ en Euskal Herria, Txalaparta, Tafalla, 2016.

Delgado, Ander, «No importa la música sino el grito. Música popular y política en el País Vasco (1960-1980)», en KorTAZAR, Jon (ed.), Autonomía e ideología. Tensiones en el campo cultural vasco, Iberoamericana Vervuert, Madrid, 2016, pp. 299-335.

ElorZA, Antonio, «Gabriel Aresti y la «gaztedi berria»», Cuadernos de Alzate, n. ${ }^{\circ} 43,2010$, pp. 57-67.

Espinosa, Pedro y López Aguirre, Elena, Hertzainak. La confesión radical, Pepitas de Calabaza y Aianai, Logroño, 2013.

ESTEBARANZ, Jtxo, Tropikales y radicales. Experiencias alternativas y luchas autónomas en Euskal Herria (1985-1990), Likiniano-Gatazka, Bilbao, 2007.

ESTORNÉS, Idoia, «Abandonando la casa del padre. Eusko Langileen Alkartasuna - Solidaridad de Trabajadores Vascos (movimiento socialista de Euskadi), 1964-1969», Historia Contemporánea, n. . 40, 2010a, pp. 127-159.

ESTORNÉS, Idoia, «Una polémica sobre el vascuence en tiempos de silencio», Cuadernos de Alzate, n. ${ }^{\circ}$ 42, 2010b, pp. 92-110.

EYERMAN, Ron, «Music in movement: cultural politics and Old and New Social Movements», Qualitative Sociology, vol. 25, n. ${ }^{\circ}$ 2, 2002, pp. 443-458.

FERnANDEZ AZKARAI, Andoni, Mierda de Bizkaia y sus grupos punk maqueteros 1977-1989, Sin Gluten y DDT, Bilbao, 2018.

Frith, Simon, «Música e identidad», en Hall, Stuart y Du GAY, Paul (comps.), Cuestiones de identidad cultural, Amorrortu, Buenos aires, 2003, pp. 181-213.

Herreros, Roberto y LóPez, Isidro, El estado de las cosas de Kortatu. Lucha, fiesta y guerra sucia, Lengua de Trapo, Madrid, 2014.

HERRI BATASUNA. 20 AÑOS DE LUCHA POR LA LIBERTAD, 1978-1998, Pamplona: Herri Batasuna, 1999.

IJURKo, Jon y OTAMENDI, Koldo, «Punk-Oi! eztanda Gipuzkoan», Xirika mskl, n. ${ }^{\circ} 2,2007$.

IRIONDO, Joxemari, «La nueva canción vasca», en Canción popular vasca. Bertsolarismo, canción antigua, nueva canción, Pop-rock, Ostoa, Lasarte, 2001, pp. 68-86.

IRIONDO, Joxemari, «Euskal musika giroa 1960ko hamarkadan», Jakin, n. ${ }^{\circ} 200$, 2014, pp. 77-94.

KASMIR, Sharyn, «From the margins: punk rock and repositioning of ethnicity and gender in Basque identity», en Douglass, William A. et al. (eds.), Basque cultural studies, University of Nevada, Reno, 1999, pp. 178-204.

KNÖRR, Gorka, «Euskal kanta berriaren historiaz», Jakin, n. ${ }^{\circ} 4$, 1977, pp. 8-15.

LAHUSEN, Christian, «The aesthetic of radicalism: the relationship between punk and the patriotic nationalist movement of the Basque Country», Popular Music, vol. 12, n. ${ }^{\circ}$ 3, 1993, pp. 263-280. 
LARRINAGA, Josu, Euskal musika kosmikoak. Euskal musika popularra gizartearen isla eta aldatzailea, Baga-Biga, Mungia, 2016.

LETE, Xabier, «Kanta berria, erresistentzi abestia», Jakin, n. ${ }^{\circ} 4,1977$, pp. 16-28.

LETE, Xabier, (Auto) Biografia bat. Alberdania, San Sebastián, 2011.

LóPEZ AguirRe, Elena, Del txistu a la telecaster; crónica del rock vasco, Aianai, Vitoria, 1996.

LóPEZ AguirRe, Elena, Historia del rock vasco. Edozein herriko jaixetan. Aianai, Vitoria, 2011.

López Romo, Raúl, Años de claroscuro. Nuevos movimientos sociales y democratización en Euskadi (1975-1980), UPV/EHU, Bilbao, 2011.

Martin, Peter J., «Music, identity, and social control», en Brown, Steven y Volgsten, Ulrik (eds.), Music and manipulation. On the social uses and social control music, Berghahn, Oxford, 2006, pp. 57-73.

Martín Santos, José A., «Las noticias sobre ETA en la música vasca (19722012). El rock como documentación informativa», Mediatika, n. ${ }^{\circ}$ 14, 2013 , pp. 67-82.

Mata, José Manuel, El nacionalismo vasco radical. Discurso, organización y expresiones, UPV/EHU, Bilbao, 1993.

MERINO, F. Javier, La izquierda radical ante ETA. ¿El último espejismo revolucionario en occidente?, Bakeaz, Bilbao, 2011.

Moso, Roberto, Flores en la basura. Los días del Rock Radikal, Hilargi, Bilbao, 2004.

Mota, David, « ¿Fuimos ratas en Bizkaia? Las letras de Eskorbuto y su crítica sociopolítica (1983-1988)», en Collado, Carlos (ed.), Himnos y canciones. Imaginarios colectivos, símbolos e identidades fragmentadas en la España del siglo XX, Comares, Granada, 2016, pp. 313-330.

Mota, David, Los 40 radikales. La música contestataria vasca y otras escenas musicales: origen, estabilización y dificultades (1980-2015), Beta, Bilbao, 2017.

OronOz, Belen, Gazteri berria, kantagintza berria. Euskal Kantagintza Berriaren ( Ez dok Amairu») eta Nova Canço Catalana-ren ( «Els setze Jutges») arteko azterketa konparatiboa, Erein, San Sebastián, 2000.

Pascual, Jakue, Telúrica vasca de liberación. Movimientos sociales y juveniles en Euskal Herria, Likiniano Elkartea, Bilbao, 1996.

Pascual, Jakue, Movimiento de resistencia. Años 80 en Euskal Herria. Contexto, crisis y punk, Txalaparta, Tafalla, 2015.

PIESlaK, Jonathan, Radicalism \& music. An introduction to the music cultures of Al-Qaída, racist skinheads, Christian-affiliated radicals, and eco-animal rights militants, Wesleyan University Press, Middleton, 2015.

PorraH, Huan, Negación punk en Euskal Herria, Txalaparta, Tafalla, 2006.

Rowe, David, Popular cultures. Rock music, sport and the politics of pleasure, Sage, Londres, 1995. 
SAEnz Del CAStillo, Aritza, «El Rock Radical Vasco y las identidades nacionales presentes en el País Vasco durante la transición y primeros años de la democracia», en Collado, Carlos (ed.), Himnos y canciones. Imaginarios colectivos, símbolos e identidades fragmentadas en la España del siglo XX, Comares, Granada, 2016, pp. 297-312.

SANCHEZ EKIZA, Karlos, «Radical Rock. Identities and utopies in Basque popular music», en Martinez, Sílvia y Fouce, Héctor (eds.), Made in Spain. Studies in popular music, Routledge, Londres, 2013, pp. 42-52.

STREet, John, Política y cultura popular, Alianza, Madrid, 2000.

STREeT, John, Music and politics, Polity, Cambridge, 2012.

Trecet, Ramón y Moreno, Xabier, Me queda la palabra, Dédalo, Madrid, 1978.

TuRINO, Thomas, Music as social life. The politics of participation, University of Chicago Press, Chicago, 2008.

Velez de Mendizabal, Josemari, Badok 13. Eusko Ikaskuntza, San Sebastián, 2008.

Velez de Mendizabal, Josemari, «Maite Idirin / Abeslaria», Euskonews, n. ${ }^{\circ}$ 569, 4-11.03.2011 [Consultado el 26.08.2017 en http://www.euskonews. com/0569zbk/elkar_eu.html]

WORLEY, Matthew, «Shot by both sides: Punk, politics and end of "Consensus"», Contemporary British History, vol. 26, n. ${ }^{\circ}$ 3, 2012, pp. 333-354.

Zabala, Juan Luis, Jesus Mari Artze. Ttakunaren esku isila, Zumarte, San Sebastián, 2003.

\section{Financiación}

Este trabajo se ha realizado en el marco del grupo de investigación del Sistema Universitario Vasco IT-708-13 y el grupo de investigación del Ministerio de Economía y Competitividad HAR2014-51956-P y HAR2017-83955-P.

\section{Datos de los autores}

Ander Delgado (ander.delgado@ehu.eus) Doctor por la Universidad del País Vasco/Euskal Herriko Unibertsitatea desde 2006 y, en la actualidad, profesor en el Departamento de Didáctica de las Ciencias Sociales de la Facultad de Educación de Bilbao (UPV/EHU). Su inicial línea de investigación se centró en el estudio de la politización en el entorno rural vasco entre el siglo XIX y XX. Dentro de esta línea ha publicado varios libros y artículos en revistas como Ayer, European History Quarterly o Journal of Social History. En la actualidad investiga sobre los movimientos culturales y educativos en los años 60 y 70 en el País Vasco. En esta línea de tra- 
bajo ha publicado artículos en History of Education, Aula o Journal of Educational Media, Memory, and Society. También desarrolla una línea de trabajo sobre el currículo de Historia y materiales educativos en el País Vasco durante el periodo democrático.

Ekaitz Etxezarreta (ekaitzetxezarreta@gmail.com) Licenciado en Historia por la Universidad del País Vasco/Euskal Herriko Unibertsitatea y profesor de Educación Secundaria. Sus líneas de investigación han estado centradas en la historia de la música y de los movimientos sociales y culturales vascos contemporáneos. 